\title{
A PROPÓSITO DEL MAESTRO IGNORANTE Y SUS LECCIONES: TESTIMONIO DE UNA RELACIÓN TRANSFERENCIAL
}

\author{
Graciela Frigerio*
}

\begin{abstract}
RESÚMEN: El artículo remite a la producción y trayectoria de Rancière como un modo de nombrar una filosofía extramuros. Desde esta extraterritorialidad, transitando nociones del psicoanálisis, Frigerio da cuenta de la pertinencia pedagógica y la actualidad de las lecciones de Rancière para los educadores que hoy, en América Latina, tienen a su cargo la responsabilidad de educar. El texto puede recorrerse en clave de transferencia. Destaca los modos en los que el amor de transferencia se vuelven condición de emancipación cuando ofrecen la regla de la confianza como encuadre de una pedagogía. Insiste en destacar que es posible interrumpir las profecías de fracaso que acompañan la relación con la cultura, de modo que el origen social deje de ser una marca que actúa como condena. Un amor de transferencia puede ofrecer una salida de la condena sin que implique renegar de la pertenencia; puede permitir que cada sujeto recupere la oportunidad de no quedar atrapado en el origen, cuando la asimetría fundante de las relaciones no deviene la sede de una desigualdad. La igualdad se transforma, entonces, en una condición de la emancipación posible.
\end{abstract}

Palabras clave: Transferencia. Amor de transferencia. Objeto transicional. Regla fundamental.

\section{ON THE IGNORANT SCHOOLMASTER AND HIS LESSONS: TESTIMONY OF A TRANFERENTIAL RELATIONSHIP}

ABSTRACT: This paper refers to the production and trajectory of Rancière as a way of developing an outsider philosophy. From this extraterritoriality, through psychoanalytic concepts, Frigerio rescues the pedagogical relevancy and topicality of the lessons of Rancière

Investigadora y directora de proyectos del Centro de Estudios Multidisplinarios (Buenos Aires, Argentina).E-mail: gracielafrigerio@arnet.com.ar ou info@cemfundacion.org.ar.

Educ. Soc., Campinas, vol. 24, n. 82, p. 267-274, abril 2003 
for the teachers nowadays in charge of education in Latin America. This text can be used as a clue about transference. It emphasizes the different ways transfer love follows to become a condition for emancipation when it offers trust as a framework for pedagogy. It also stresses that it is possible to interrupt the failure prophecies related with culture, so that nobody be condemned for their social origins. Transfer love may offer a way out of condemnation without denying the place or group to which one belongs; it can also hinder that anyone be trapped in their origins, especially when the founding asymmetrical relationships transforms into inequality. Thus, equality is a condition for possible emancipation.

Key words: Transference. Transfer love. Transitional objet. Fundamental rule.

7 modo de inicio de esta nota destinada a festejar la traducción de un libro (rebelde con causa a toda explicación), para el cual es dable esperar una recepción cuya resonancia tenga larga vida, permítanme referirme a algunos aspectos de la obra del autor y hacerlo desde el territorio donde la obra me cautivó dejándome libre, es decir en el lazo que siempre instituye una relación transferencial.

La transferencia es, como el psicoanálisis lo deja entender, el proceso que actualiza deseos inconscientes en el marco de una relación, se trata de un desplazamiento que da lugar a una suerte de equívoco: alguien cree que el otro es lo que el otro no es, alguien elige un destinatario allí donde no hay nadie, o donde hay un hueco. La transferencia permite sentir, erróneamente, que algo nos está singularmente dirigido. Por eso puedo afirmar la siguiente sinrazón: los libros de Rancière me han hablado antes de que pudiera conocerlo, antes que él me dirigiera la palabra. La transferencia genera la ocasión de una elaboración cuando una regla garantiza un trabajo que no reniegue de ella.

La obra de Rancière tiene, para mí, algo conmovedor. Podríamos pensar que es en la escritura (ese non sens diría Duras al definir el escribir: Eso que es no hablar. Que es callarse, 1998, p. 28) donde el filósofo se hace a la vez emoción y razón. Donde la obsesividad del trabajo minucioso desaparece bajo la poesía de la forma. El trazo se vuelve voz y la palabra invita con sencillez a cada uno a pensar por sí mismo. La producción de Rancière es por ello, pero no sólo por ello, Jacotista, si esto pudiera decirse. Nos confronta una y otra vez a un enigma, a un mensaje para el que propone una traducción y deja a nuestro cargo la interpretación.

Hace ya varios años algunos de los escritos de Rancière me acompañan. Dí con ellos gracias a algunos entrañables amigos: Patrice 
Vermeren y Stephane Douailler. Sus libros, leídos en desorden, con placer no desprovisto de pausas de desasosiego, se han vuelto con el correr de los tiempos una suerte de compañeros de camino, interlocutores. Digamos que si "maître est celui qui maintien le chercheur dans sa route" (Rancière, 2002, p. 57), ahí donde cada uno en comunicación con otro no deja de estar solo buscando, como afirma la lección del maestro ignorante, Rancière tiene titularidad en el arte de enseñar.

Cada tanto releo y delineo una línea que da cuenta de un nuevo subrayado, hago alguna anotación a un margen ya poblado. Me sorprendo con algún sentido que me había pasado desapercibido. Hallo una nueva razón para afirmar su contemporaneidad. Cada libro resultó una invitación. Tal vez escribir sea la manera que eligió ese hombre menudo, tan tímido como riguroso, tan exigente consigo mismo como sensible y solidario con las causas justas, para poner en acto una pedagogía de transferencia cuyo tránsito, a sabiendas de un maestro que no lo sabe todo, instituye al pensar como el territorio de una habilitación para la gramática singular de cada sujeto y para la gramática de lo plural. ¿Habría otra pedagogía posible si hablamos de emancipación intelectual?

No se trata de hacer de la transferencia una pedagogía sino de aceptar que una pedagogía no explicadora se funda en el reconocimiento de una transferencia, que hace posible no sólo que alguien enseñe hasta lo que no sabe, sino que alguien se emancipe al aprender lo que no es curricularmente enseñable. Es decir, lo que no cabe en la prescripción, lo no traducible en términos de ninguna didáctica, de ningún contenido, de ninguna competencia. Aquello que no se deja capturar en nombre de una disciplina y que desborda lo curricular.

Recurrimos a la noción de pedagogía de transferencia teniendo como horizonte la noción de relación de objeto.

Rancière es sin duda un maestro, un maître à penser, (lo afirmaremos aun cuando imaginamos que él podría discutir esa descripción), cuya escritura es una filosofía devenida traza y trazo, huella en la que se pueden percibir las marcas que dejaron en él todos aquellos que rigurosamente estudió, investigó, analizó, los que leyó contrastando luces y sombras (ver La nuit des proletaires). Al mismo tiempo cada uno lleva su propia marca, reorganización creadora, autoría, firma, nombre propio.

Su estilo tiene todo del rigor de un pensamiento crítico y como ya dijimos, no poco de poesía, aúna en las frases la complejidad de un pensar sin concesiones y la ternura de una narración que no se propone agregar a la sofisticación de la idea ningún componente que obstaculice el diálogo. 
El contenido no elude los compromisos con lo que está más allá de la tapa del libro (leer Aux bords du politique, donde Rancière evoca los sentimientos que genera el tema de la comunidad de iguales); en la frontera de la disciplina, adentrándose en los huecos de las instituciones (leer su trabajo en La grève des philosophes, texto donde interroga acerca del lugar de la filosofía en el sistema educativo y el de la filosofía enseñable en ese lugar), en los intersticios de las tramas y en el descarnado territorio de lo social ahí donde el hombre aún aúlla (leer Breves viajes al país del pueblo, páginas donadas a los "sin parte"). Más recientemente aun explora una estética co-fundante del inconsciente en una osadía conceptual (leer L'inconscient esthétique).

Toda la obra dialoga con los de un terruño, el de la filosofía, proponiendo tanta filiación simbólica como sosteniendo la apertura de una extranjeridad siempre refrescante. Toda la obra anuda la inquietud por la subjetivación de lo político, por los paisajes ríspidos de la política, la igualdad como punto de partida y horizonte de toda travesía, la plaza a la palabra de hombre que todo hombre puede enunciar y todo hombre, como tal, responder (una lección del maestro ignorante). A la vez, la escritura de Rancière puede pensarse como su manera de invitar a los no filósofos a una aventura filosófica, la manera de concretar la intención de una filosofía extramuros.

Es en el territorio de la pedagogía o mejor dicho en el territorio de fronteras difusas de lo que queda de la escuela en América Latina, allí donde las políticas rehuyeron a la justicia de lo político, es allí donde no ceso de encontrar actualidad y vigencia para las lecciones del maître ignorant.

En efecto, el maestro ignorante da clase para los que entendemos que educar es el acto político de distribuir la herencia, bajo la modalidad de un don que no conlleva deuda y designando al colectivo como heredero (Frigerio, 2002, p. 5-16); para los que afirmamos que educar es hoy un acto de resistencia a la reproducción de desigualdades (Frigerio, en prensa); para los educadores que cotidianamente se enfrentan a las condiciones adversas de una economía que desprecia al hombre, para los que descreen de las políticas que desconocen la justicia para todos, el maestro ignorante regala su lección emancipadora al sostener sin explicar nada, que mediante nuestra intervención (ejercicio pleno del actopoder como podría definir G. Mendel) es posible interrumpir el cumplimiento de las profecías de fracaso encarnadas en los cuerpos frágiles de los niños de los sectores populares.

El maestro ignorante nos enseña que: es posible enseñar la democracia que desconocemos, crear condiciones para que otros aprendan lo 
que no sabemos. Nos dice también que las tentaciones tecnocráticas tienen, como los pragmatismos tan de moda, un límite en cada educador, cuando el educador decide que es posible para todos, (con la única condición de otorgarles confianza, Cornu, 2002), aprender las lenguas desconocidas de todas las ciencias. Que corresponde a la escuela pública sostener una oferta para la que puede no haber demanda y a todo educador analizar la pertinencia de las demandas antes de plegarse a la tiranía de una globalización que deshace mundo. Que enseñar todo a todos quizás no por antigua devino consigna vieja.

El maestro ignorante descree de las metodologías explicadoras, denuncia en su lección que el didactismo (hoy tan en boga) embrutece, poniendo falsas certezas ahí donde deberían sostenerse las incertidumbres. La plaza del maestro ignorante ofrece una estructura simbólica próxima a la figura del analista supuesto saber. Sabe acerca de su puesto, de su plaza, cuando desafía a los destinos de fracaso para decir: puedes ver, puedes sentir, puedes pensar, puedes querer, puedes hacer. Es su oferta la que crea la demanda. Es su apuesta sin condición la que emancipa, es el carácter gratuito de su enseñanza y de su intento lo que contribuye a que otro piense. El maestro emancipador sólo ofrece un marco, sólo brinda un encuadre, hace sin saberlo de apuntalamiento al trabajo psíquico del otro. Quizás, ignorándolo como tal, despliega un trabajo psíquico sobre sí, descreyendo del espejismo de la certeza del método explicador, se anima a aventurarse en una relación de desconocido (Rosoltato, 1975). Trabajo psíquico sobre el enigma que toma nombres y excusas distintas para decir y decirse.

\section{La transferencia en las relaciones pedagógicas}

En todos los casos, se trata de una relación tan interesante y compleja como imprescindible para que algo se aprenda. Sede de un desplazamiento, punto de apoyo de un amor incómodo, tan des-actualizado como actual, un amor no pertinente, mal à propos como podría decir Octave Mannoni. Este amor deviene siempre que se resista a ser correspondido, la condición de un trabajo de elaboración. De una alteridad que, convocada desde una asimetría fundante, propicia una igualdad y anuncia una mayoría de edad aun para los menores con necesidad de un tutor o encargado.

Por supuesto el error estaría en creer que se trata del otro en sí, es del otro de sí del que se trata. Sabemos que es menos cuestión de un Telémaco y más de un Ulyses fugitivo a toda relación de eternidad, renuente a toda inmortalidad obtenida al precio de un aislamiento lo 
que Fénelon pone en juego en el comienzo del texto elegido por Jacotot, que brinda a Rancière la materia prima de sus lecciones de emancipación. En esa línea: Telémaco - Ulyses; Ulyses - Telémaco - Fénelon; Fénelon - Jacotot; Jacotot - Rancière, la filiación (simbólica) mueve al sujeto.

Sobre esto nos habla un Rancière/Jacotot. Y nos lo dice de mil maneras. Haciéndose cargo al rescatar de los tiempos el pensamiento de ese profesor/político/exiliado, alérgico a toda metodología embrutecedora, que no duda en dar el mote despectivo de "La Vieja" para referirse a la pedagogía que todo el tiempo afirma que sin ella, sin la varita mágica de su explicación, el mundo permanecerá mudo.

Podemos hacer la hipótesis, afirmarlo sería demasiado presuntuoso, que entre Rancière y Jacotot, siglos mediante, la transferencia trabaja, la filiación se firma bajo la excusa de una transmisión.

Que Jacotot algo de amor sabía nos lo hace suponer la elección de un texto que se inicia con la narración de un encuentro, que genera una oferta de amor. El amor de Calipso para empezar, amor mal à propos en lo que concierne a Telémaco. Pero también relato de amor à propos en el caso del vínculo entre dos generaciones, entre un padre y un hijo. Igualmente amor à propos por arte de gobernar con respeto y justicia.

Entre Jacotot y sus estudiantes Telémaco trabaja al modo de objeto transicional como Winnicott denomina la posibilidad de conciliar una oferta de sentido con una significación asignada. Objeto estructurante que no puede hallarse sin oferta y que no deviene tal sin hallazgo. (Entendemos que las lecciones de Rancière tendrán el mismo carácter).

Jacotot, quien es cuestión y excusa de las lecciones de Rancière, propuso a los estudiantes, a falta de idioma común, una narración traducida. Digamos que su trama no deja indiferente a ningún lector: un hijo en búsqueda de padre; una esposa/madre a la espera, que teje y desteje trampas para detener los tiempos; figuras seductoras con capacidad de promesa; una figura protectora femenina transvestida bajo la forma de un tutor; un trasfondo de guerras y conflictos; la pelea permanente contra las fuerzas de la naturaleza - interna y externa -; la inquietud por el buen gobernar; una demanda de reconocimiento.

La lección señala que la traducción no explica, ni impone ninguna interpretación, queda disponible a la espera de un estudiante/intérprete que se apropie de las palabras, explore sus equivalencias y analice sus alcances.

La traducción ofrecida se instala en un encuadre que genera las condiciones para el trabajo de la palabra. Podríamos decir que está a 
disposición y se solicita una asociación libre al tiempo que sujetada a una regla fundamental que la contiene y significa (no de cualquier modo).

El encuadre, al establecer sus fronteras, esto es una clase: donde se afirma aquí se enseña (hasta lo que no se sabe dirá el maestro ignorante) por que se sabe que las inteligencias son iguales, que es la confianza depositada, la apuesta, la que reactualiza la ocasión de un contrato narcisista (expresión que debemos a Piera Aulagnier) que ofrece una oportunidad.

La oportunidad iguala. Así un padre analfabeto no estará imposibilitado de acompañar los logros de la adquisición de la lectura de su hijo, un niño down podrá aprender una lengua tercera, un adolescente podrá enamorarse de las matemáticas y hasta de una vertiginosa geometría (como ejemplifica J.-B. Pontalis).

La igualdad no anula la asimetría, la respeta y la compensa. La asimetría debe garantizar que ninguna diferencia devenga la sede de una desigualdad. La asimetría funda la transferencia, que funda la confusión que termina volviendo posible que, un error de partida: el otro me confunde, no soy quien cree, confundo al otro con quien no parece ser, devenga la clave de una emancipación que afirma: no puedo ser sin otro, pero el otro no se aprovecha de ello, no me somete, no me domina, no me aliena, no se cobra. En consecuencia no estoy en deuda con él. Por eso mismo, al maestro ignorante, cuyo sinónimo en este marco se define en términos de un maestro emancipador, todo mi agradecimiento.

Recebido e aprovado em fevereiro de 2003.

\section{Referencias bibliográfícas}

CORNU, L. Responsabilidad, experiencia, confianza. In: FrIGerIo, G. (Comp.). Educar: rasgos filosóficos de una identidad. Buenos Aires: Santillana, 2002. p. 43-83.

DURAS, M. Ecrire. Paris: Folio, 1998. p. 28.

FRIGERIO, G. Educar: una filosofía del tiempo. Ensayos y Experiencias, Buenos Aires, n. 44, p. 5-16, 2002.

FRIGERIO, G. Contra lo inexorable. Buenos Aires: GCBA/CEPA (en prensa).

LAPLANCHE, J. La prioridad del otro en psicoanálisis. Buenos Aires: Amorrortu, 1996. 
LAPLANCHE, J. Entre seducción e inspiración: el hombre. Buenos Aires: Amorrortu, 2001.

MENDEL, G. L'acte est une aventure. Paris: La découverte, 1998.

PONTALIS, J.-B. Fenêtres. Paris: Folio, 1999.

RANCIERE, J. La nuit des proletaires. Paris: Fayard, 1981.

RANCIERE, J. Nous qui sommes si critiques. In: DERridA, J. et al. La grève des philosophes: ecole et philosophie. Paris: Osiris, 1986. p.110-121.

RANCIERE, J. Le maître ignorant. Paris: Fayard, 1987. (Em português: Belo Horizonte: Autêntica, 2002).

RANCIERE, J. Aux bords du politique. Paris: Osiris, 1990.

RANCIERE, J. Courts voyages au pays du peuple. Paris: Seuil, 1990.

RANCIERE, J. Les mots de l'histoire: essai de poétique du savoir. Paris: Seuil, 1992.

RANCIERE, J. La mésentente. Paris: Galilée, 1995.

RANCIERE, J. Aux bords du politique. Edition remanié. Paris: La fabrique, 1998.

RANCIERE, J. La parole muette. Paris: Hachette, 1998.

RANCIERE, J. L'inconscient esthétique. Paris: Galilée, 2001.

ROSOLTATO, G. La relation d'inconnu. Paris: Gallimard, 1975.

WINNICOTT, D. W. De la pédiatrie à la psychanalyse. Paris: Payot, 1971. 